\title{
Analyzing of Flow in Open Channels Networks Using HEC-
}

\section{RAS}

\section{Shayannejad M11, Ostad-Ali-Askari $\mathrm{K}^{2 *}$, Eslamian $\mathrm{S}^{1}$, Singh $\mathrm{VP}^{3}$ and Dalezios $\mathrm{NR}^{4}$}

${ }^{1}$ Department of Water Engineering, Isfahan University of Technology, Isfahan, Iran

${ }^{2}$ Department of Civil Engineering, Isfahan (Khorasgan) Branch, Islamic Azad University, Isfahan, Iran

${ }^{3}$ Department of Biological and Agricultural Engineering \& Zachry Department of Civil Engineering, Texas A and M University, 321 Scoates Hall, 2117 TAMU, College Station, Texas 77843-2117, USA

${ }^{4}$ Laboratory of Hydrology, Department of Civil Engineering, University of Thessaly, Volos, Greece \& Department of Natural Resources Development and Agricultural Engineering, Agricultural University of Athens, Athens, Greece

*Corresponding author: Kaveh Ostad-Ali-Askari, Department of Civil Engineering, Isfahan (Khorasgan) Branch, Islamic Azad University, Isfahan, Iran, Tel: (+98)-31-35354001-9; Email: Koa.askari@khuisf.ac.ir

\section{Abstract}

This article shows a pliable unified modeling scheme applying a materially based, distributed, integrated hydrological and water quality modeling organization. It is need to analyze the unsteady flow in open channels network is done using the computer packages, because solving the Saint-Venant equation is very difficult and sophisticated spatially for a network of channels. The unsteady flow can be analyzed by Saint-Venant equations. These equations can be solved by characteristics and finite difference methods. The HEC-RAS program applies the second method.

This program need to data such as: scheme of network channels, geometric properties of cross sections, initial discharge and boundary condition. The outputs of this program are: Surface profiles, flow hydrograph and distribution of flow velocity in each cross section etc. In this research an example was solved in unsteady flow using HEC-RAS. In this procedure, the energy and duration equations are decided for steady, slowly diverse flow by the Newton-Raphson procedure and the offered methodology is used to tree-type and looped-channel networks. An algorithm is introduced to define numerous critical depths in a compound channel. Corrections in channel geometry are provided to prevent the incidence of, many critical depths. The incidence of only one critical depth in an implicate cross section with improved geometry is shown for a tree-type channel network.

Keywords: Land use; Forest; Rural farming; Nigeria 


\section{Introduction}

The Saint-Venant fundamental equations (or SaintVenant's principle), first presented in 1871, present a complete form of the governing forces of the flow.

Solving these equations, especially in a network of canals or open channels with irregular sections, is a very complex and time taking task [1]. It is compulsory to use computer models and programs. By using such models, profile of water levels can be plotted in each branch of the channel network at any time.

Also, the flow of hydrograph can be anywhere gained from the network [2]. The flow graph shows the current fluctuations in flow changes relative to time, which is the reason for such changes there may be several factors, including changes in the input to the grid, flood into the river, or breaking of the dam [3]. One of the models in this area is the FLDWAV model, which is the result of three decades of efforts by National Center experts American
Meteorology [4]. This model combines two models of DWOPRE and DAMBRK, the main idea of which is by Freed and his co-worker Lewis was following it. The two researchers have published numerous articles on the introduction of the application and Comparison of the results of the FLDWAV model with other models has been published. The model of the output hydrograph generated in effect Simulates the failure of the dam, and the motion of the wave in the downstream stream [5].

Parvaresh and Koochakzade in (2001) The KaroonRiver were tested by a theme, and the results of this study showed that the model had an acceptable adaptation to the observations.

Another one Models of network flow analysis in the open channel of the HEC-RAS model [6]. Version 3/01 of this model was released in 2001 by the Center the American Army Hydrology Engineering has been developed. In this study, the model is examined. (In Figure).

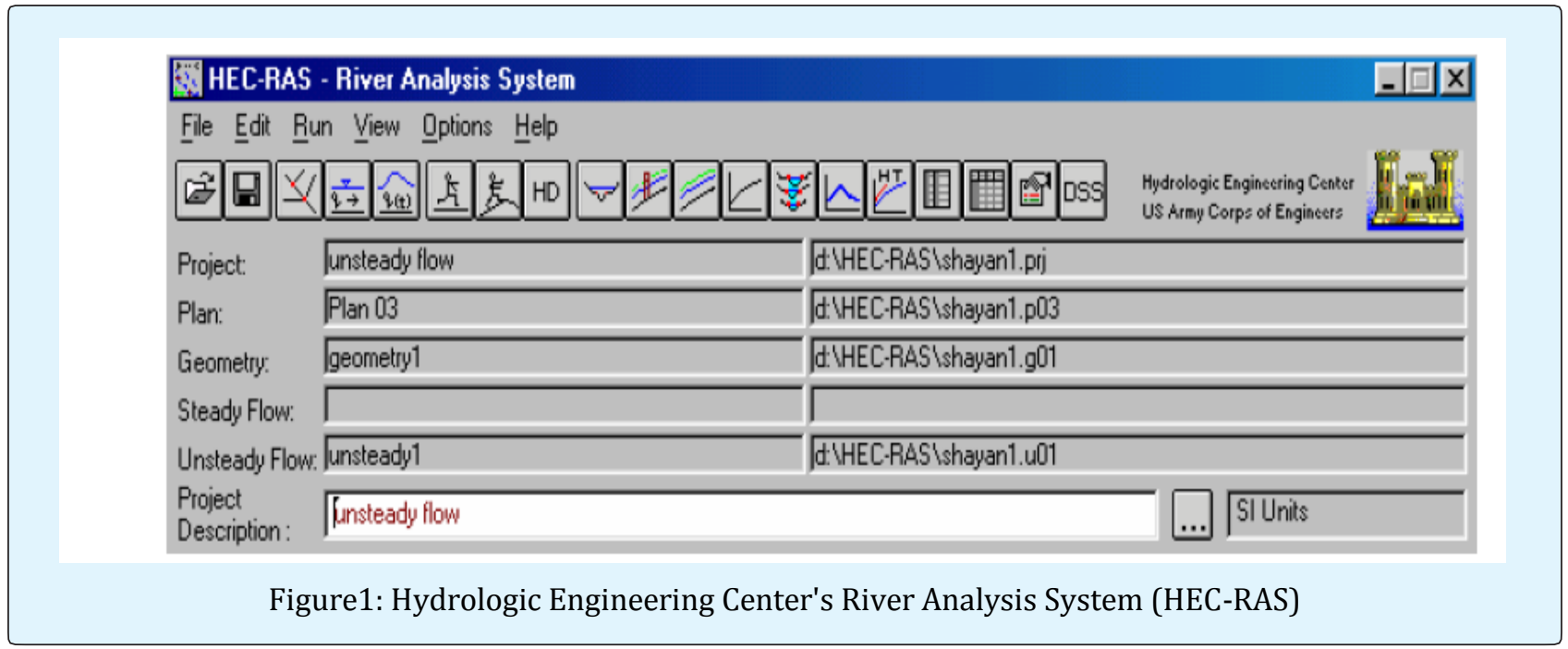

The home screen of this application is displayed. An unreliability analysis of the unsteady flow component of the one-dimensional model HEC-RAS within the universal chance unreliability assessment is introduced [7]. However, this relies on the model area and boundary situation. The urgency to identify between beneficial parameters and actual physical parameters is stricted [8]. The research shows that this analysis can be applied to generate dynamic possibility maps of flooding during an occurrence and can be linked to a stopping standard for universal probability unreliability approximation [9]. This task explains the usage of a methodology planned to amend the delineation of water surface profiles. The suggested methodology expanded herein applies HEC-RAS, a onedimensional (1D) computer code for open surface water computations, to iteratively assess hydraulic profiles along drain channels until meliorate the aquifer/drain interplay method [10]. Clear and pragmatic hydraulic profiles along drains are received while backwater traces are distinctly demonstrated [11]. With the calibrated discharge, HEC-RAS is able to generating floodplain polygons that are analogous to the satellite imagery [12]. The prime goal was to build 


\section{Journal of Ecology \& Natural Resources}

and accredit a Hydrologic Engineering Center's River Analysis System (HEC-RAS) river network model of the system applying available HEC-2 model-generated data [13]. Then, HEC-RAS simulations were maded to produce water surface profiles all over the system for six various design storm incidents [14]. ArcView GIS was coupled with HEC-RAS to generate a flood map for flood discharge of several return intervals [15].

\section{Materials and Methods}

The steps in working with RAS-HEC are as follows: 1. Draw an open-loop network and enter geometric specifications of different sections of the network (Data Geometric / Edit: (This Specifications include cross section topography, manning roughness coefficient and length of sections of the section. (figure 2)

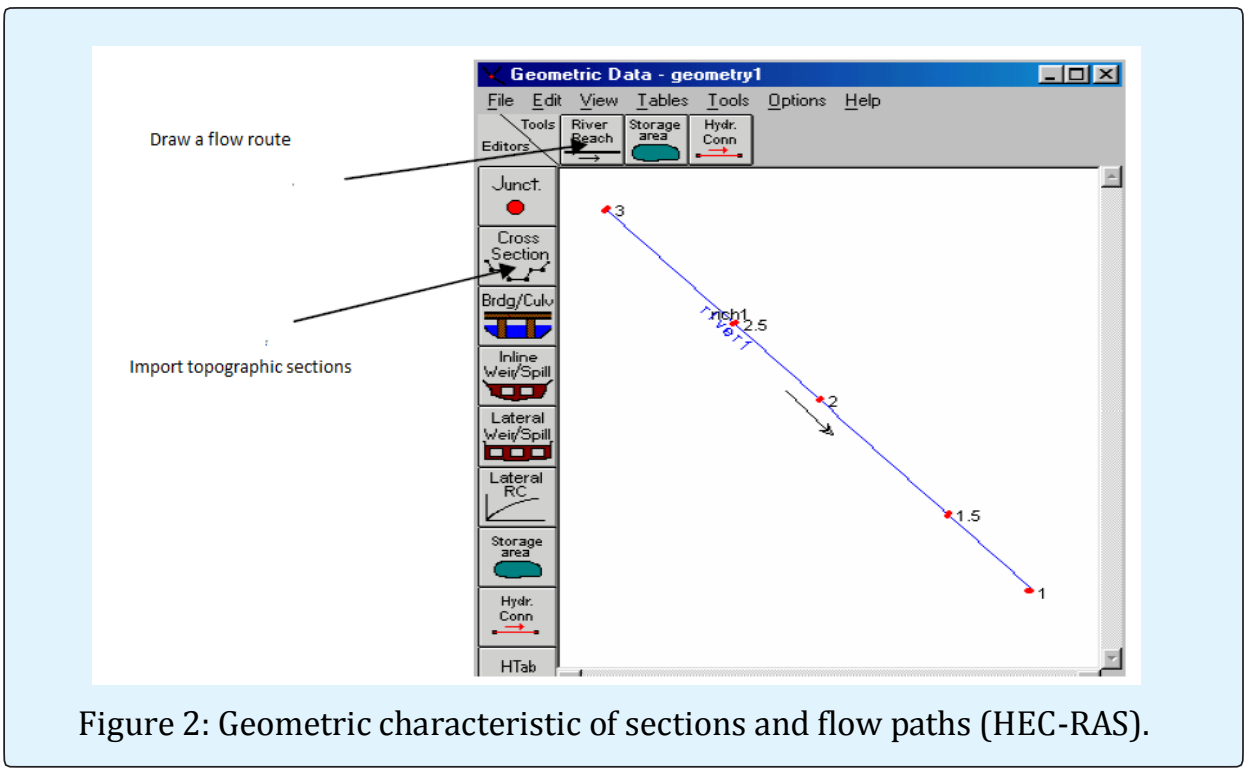

2. Entering current data (lasting or noncontinuous) (data flow an unsteady Edit (This information includes upstream and downstream conditions and initial flow conditions [16]. Upper

boundary conditions can be one the flow hydrograph and lower boundary conditions can be the flow curve (Figure 3)

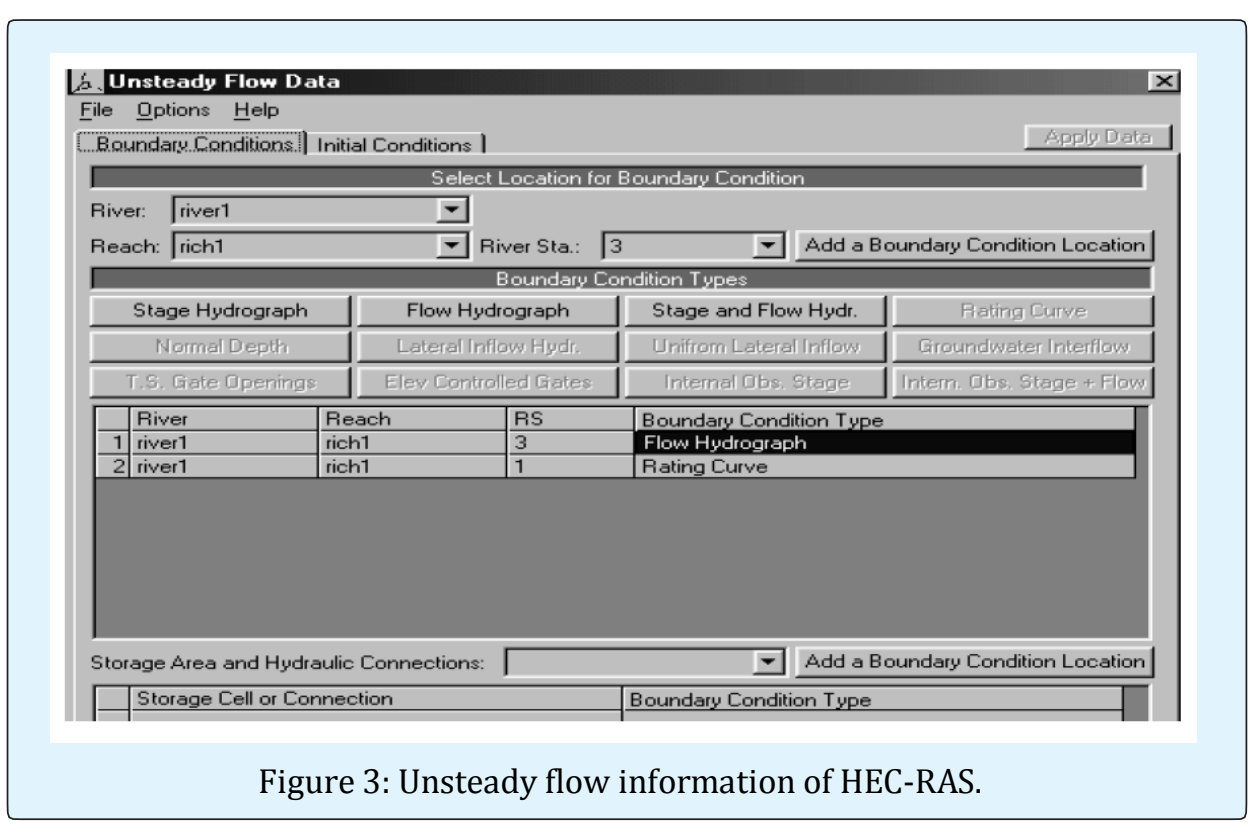


3. Run the program (analysis flow unsteady: / Run :). To run the program, you must start the startup time and start it Completion of computations and intervals of computational steps (Figure 4).

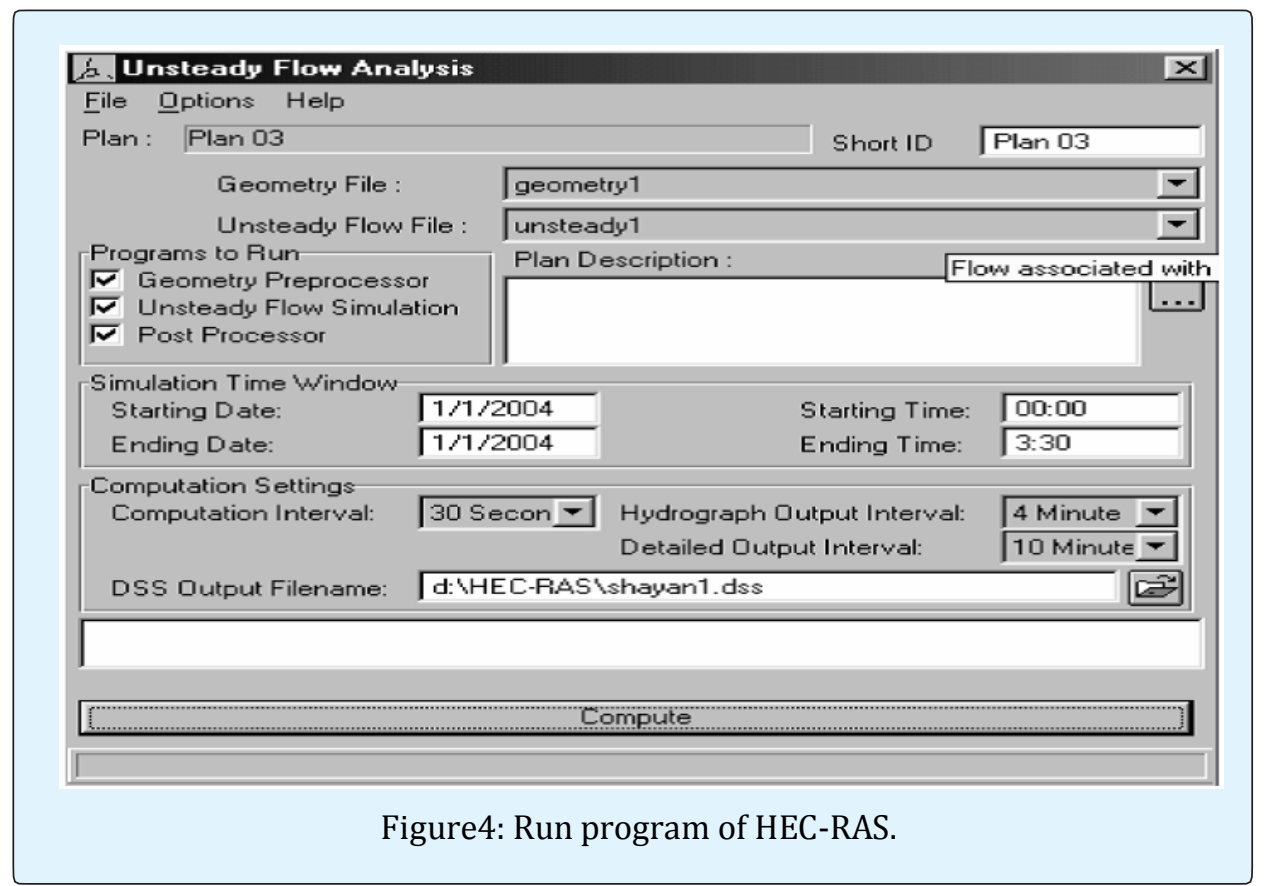

\section{Results and Discussions}

The information about a piece of a channel with the length of $2 \mathrm{~km}$ which starts with the flood of specific hydrograph and ends in a spillway is put in the model. The results are visible in the view option. The result include flow sections, profiles water level at different times, hydrograph flow in different parts, curve Discharge-Eshel, and other characteristics of the flow such as velocity, Fraud number, depth of hydraulic, shear stress, flow area, .... That is presented in figures 5-7.

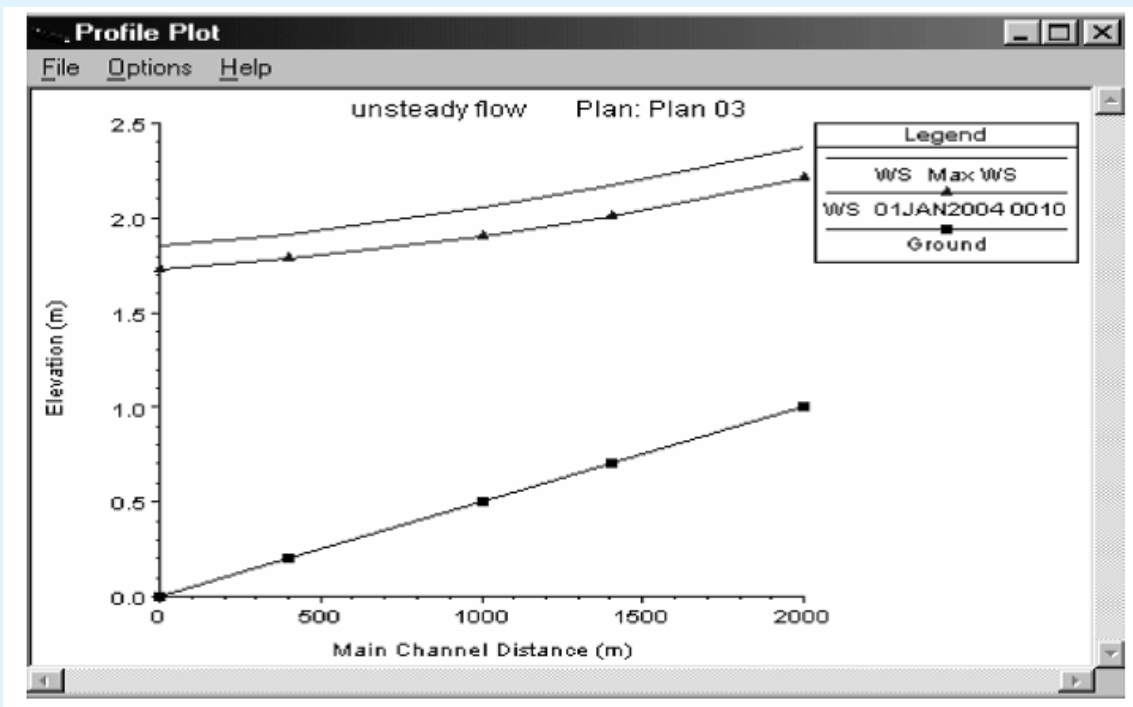

Figure 5: Draw a profile of the surface of the water at two different times by HEC-RAS model. 


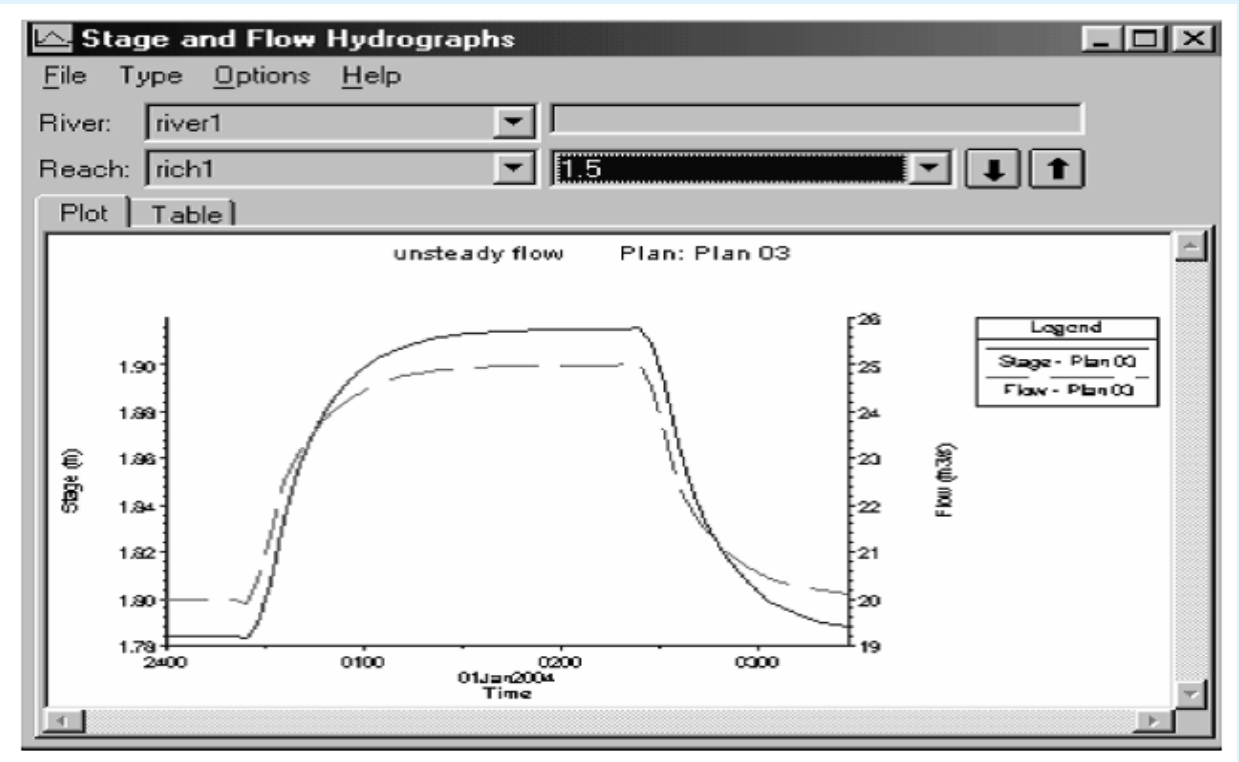

Figure 6: Draw a Discharge and Eshel Hydrograph in the distance of 1600 metres from the point starting the flood by HEC-RAS.

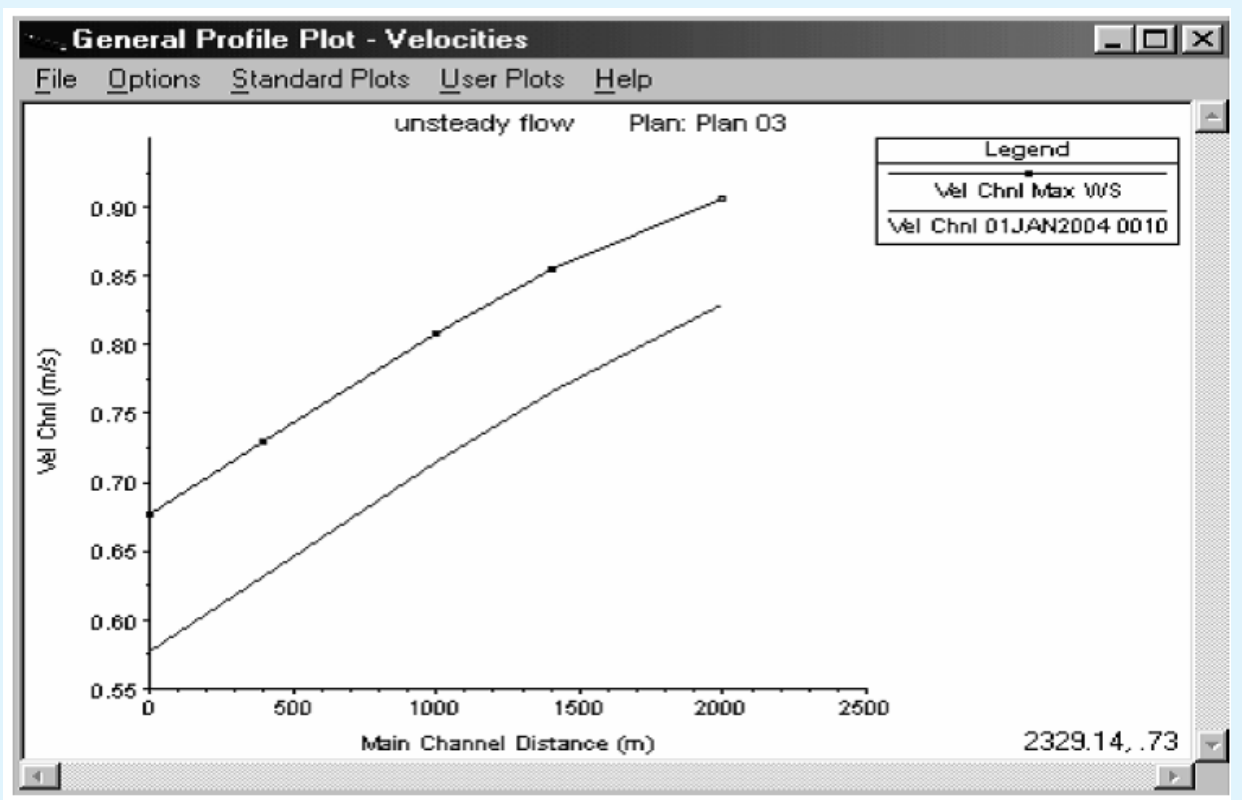

Figure 7: Draw alteration flow velocity at two different times by HEC-RAS.

However, natural channels are seldom rectangular or trapezoidal in cross portion, these cross portions are obtained for the calculation of steady, slowly diverse flow in open channel networks. The precision of the calculated conclusions, thus, becomes doubtful due to diversity in the hydraulic and geometric specifications of the main channel and floodplains [17]. As contrasted to the existing procedures, the methodology is more common and appropriate for usage to compound and trapezoidal 
channel cross parts in series channels, tree-type or looped networks.

\section{Conclusion}

Multiple hydrological studies have be seen that river discharge evidences are affected by considerable unreliability. This hesitancy is envisaged to be very high for river flow data referred to flood incidents, when the stage-discharge rating curve is extrapolated far beyond the module limit.This reading inspects the standard methodologies for the building and extrapolation of rating curves to excessive flow depths and depicts to require of suitable techniques to decrease the indecision of flood discharge data. Consequences received with HEC-RAS model were applied in compound with ArcGIS to provide floodplain maps for variant return cycles. The very different flow regime of River is determined by frequent floods with cautiously expanding and sometimes terrified peak water levels and by repeated, long-lasting low flows. The primary causes of these features are: the form of drainage basin; the discharge of tributary streams related to the one of the main channel; the high sediment transport; the low slope of the low-land reach and the tought low-flow and high-flow river channel. Routing is a procedure applied to simulate and auspicate alters in water flow along a river or channel. There are multiple hydraulic flow routing procedures that model channel flow with great precision applying lots of data related to channel geometry and specifications, so making computations very costly. In difference, hydrologic procedures are methods that clarify the computation of flow situations in a channel reach. Routed hydrographs for ordinary and composed channels are then contrasted with a river analysis system model (HEC-RAS). Those consequences show that the suggested model (HEC-RAS) procedure is beneficial in routing a stage hydrograph.

\section{References}

1. Fread DL, Lewis JM (1986) Parameter optimization of dynamic routing model, proceedings, Water forum 86: World Water Issues in Evolution, ASCE, Long Beach, CA, 443-450.

2. Fread DL, Lewis JM (1988) FLDWAV: A generalized flood rovting model, proceeding of Nation al Conference on Hydraulic Engineering, Spring, Colorado, 6pp.

3. Fread DL (1993) NWS FLDWAV Model: The replacement of DAMBRK for dam-break flood predictro, proceeding loth Anval coference of the
Association of state dam safty officials, Inc., Kansas city, 177-184.

4. HEC.U.S Army (2001) Manual of HEC-RAS. DOI: www.hec.usace.army.mil/software/hecras/documentation/HEC-RAS 5.0.

5. Pappenberger F, Beven K, Horritt M, Blazkova S (2005) Uncertainty in the calibration of effective roughness parameters in HEC-RAS using inundation and downstream level observations. J Hydrology 302(1-4): 46-69.

6. Leticia B, Rodrigueza PA, Cellob C, Vionneta A, David G (2008) Fully conservative coupling of HEC-RAS with MODFLOW to simulate stream-aquifer interactions in a drainage basin. J Hydrology 353(12): 129-142.

7. Kaveh Ostad-Ali-Askari, Mohammad Shayannejad (2015) Usage of Rockfill Dams in the HEC-RAS Software for the Purpose of Controlling Floods. American Journal of Fluid Dynamics 5(1): 23-29.

8. Knebl MR, YangaK ZL, Maidment R (2005) Regional scale flood modeling using NEXRAD rainfall, GIS, and HEC-HMS/RAS: a case study for the San Antonio River Basin Summer 2002 storm event. J Environ Manag 75(4) 325-336.

9. Yang J, Ronald DT, Bahram D (2006) Applying the HEC-RAS model and GIS techniques in river network floodplain delineation. Canadian J Civil Eng 33(1): 1928.

10. Prashanth Hr, Hanif CM, Jasim I (2014) Computation of gradually varied flow in compound open channel networks. Sadhana 39(6): 1523-1545.

11. Giuliano DB, Pierluigi C (2011) A hydraulic study on the applicability of flood rating curves. Hydrology Res 42(1): 10-19.

12. Muhammad SK, Faizan A, Tariq US (2016) Floodplain Mapping Using HEC-RAS and ArcGIS: A Case Study of Kabul River. Arabian J Sci Eng 41(4): 1375-1390.

13. Mohsin JB, Muhammad U, Raheel Q (2013) Landslide dam and subsequent dam-break flood estimation using HEC-RAS model in Northern Pakistan. Nat Hazards 65(1): 241-254.

14. Sandor K, Attila K, Janos S (2006) Experiences in Application of Hec-Ras Model Under Circumstances 


\section{Journal of Ecology \& Natural Resources}

Of Flood Waves. Flood Risk Management: Hazards, Vulnerability and Mitigation Measures pp 47-58.

15. Fallah-Mehdipour E, Bozorg HE (2013) Application of Genetic Programming in Stage Hydrograph Routing of Open Channels. Water Resources Management 27(9): 3261-3272.
16. Vaze J, Teng J, Spencer G (2010) Impact of DEM accuracy and resolution on topographic indices. Environ Modeling Software 25(10): 1086-1098.

17. Brunner GW (2010) HEC-RAS, river analysis system hydraulic reference manual. US Army Corps of Engineers Hydrologic Engineering Center (HEC), 609 Second Street Davis, Ca 95616-4687. 